\title{
REGISTROS LABORAIS NAS BIBLIOTECAS UNIVERSITÁRIAS FEDERAIS: ÉTICA, POLÍTICA E ACESSO A INFORMAÇÃO
}

\author{
REGISTROS DE TRABAJO EN LAS \\ BIBLIOTECAS DE LAS UNIVERSIDADES \\ FEDERALES: ÉTICA, POLÍTICA Y ACCESO A LA \\ INFORMACIÓN
}

\begin{abstract}
Ana Carolina de Souza Caetano - acscaetano@yahoo.com.br Mestre em Biblioteconomia pela Universidade Federal do Estado do Rio de Janeiro (UNIRIO). Bibliotecária da Universidade Federal de Juiz de Fora (UFJF)
\end{abstract}

Geni Chaves Fernandes - geni@centroin.com.br Doutora em Ciência da Informação pela Universidade Federal do Rio de Janeiro (UFRJ). Professora do Programa de Pós-Graduação em Biblioteconomia da Universidade Federal do Estado do Rio de Janeiro (UNIRIO).

\begin{abstract}
RESUMO
Introdução: O fazer bibliotecário também diz respeito aos registros de seus procedimentos laborais. Além da eficiência na administração e consistência do trabalho, eles dão transparência às diretrizes e escolhas realizadas e permitem a reavaliação periódica das ações. Autores clássicos, que conceituam o documento, enfatizam a importância do ato de documentar.

Objetivos: Mapear a existência de registros das políticas e ações laborais em bibliotecas de universidades federais brasileiras e indagar sobre os problemas éticos e falta de acesso à informação na sua ausência.

Metodologia: Mapeamento nos sítios das cinquenta e sete bibliotecas de universidades federais da disponibilização de registros oficiais contendo as políticas, planos, manuais, guias de usuários, regulamentos, dentre outros.

Resultados: $57 \%$ das bibliotecas não disponibilizam nenhum tipo de registro. A maior oferta de diferentes documentos laborais encontra-se nas bibliotecas das regiões Sudeste e Sul. Mas, ainda assim, 41\% delas não disponibiliza qualquer tipo de documento. A falta de transparência pode oportunizar injustiças e mesmo ações não éticas.

Conclusões: Nos motivos para não documentar, encontra-se a falta de diretrizes claras em documentos oficiais que norteiam a profissão e os bibliotecários universitários. Isto contradiz o princípio da lei de acesso à
\end{abstract}


informação e se mostra incoerente a profissionais e instituições que teriam, teoricamente, obrigação primária de fazê-lo.

Palavras-Chave: Ética e transparência. Políticas administrativas. Bibliotecas universitárias.

\section{INTRODUÇÃO}

As bibliotecas são instituições milenares dedicadas à reunião dos registros do conhecimento. O modo como formaram suas coleções se modificou nos distintos momentos da história em que estiveram inseridas. $\mathrm{O}$ ato de se compor e desenvolver coleções esteve atrelado não só às ideias e pensamentos da sociedade em cada contexto histórico, mas também aos seus fins práticos tais como guardar a sabedoria do passado para nos orientar hoje e no futuro, atender aos estudos universitários, auxiliar à manutenção e desenvolvimento da cultura, atender às demandas do setor produtivo, dentre outras (BATTLES, 2003, p. 210-211; BURKE, 2003, p. 97). Reuniram-se documentos não só pelo simples ato de se reunir, com intuito de abarcar todos os registros do conhecimento, reuniu-se para preservar a memória de um contexto espaço-temporal, reuniu-se pensando nos possíveis usos e necessidades de um público alvo (WEITZEL, 2012).

Organizar os registros do conhecimento, com vistas ao seu fácil acesso para os diversos usos que apresentam histórica e culturalmente, em diversos âmbitos da ação humana, é a função social do bibliotecário. No âmbito acadêmico, hoje, a biblioteca universitária tem por missão contribuir ao ensino, pesquisa e extensão em sua instituição (CUNHA; CAVALCANTI, 2008, p. 53; SANTOS; RIBEIRO, 2012, p. 36).

Registrar o conhecimento significa documentar. Criar um documento é registrar em algum suporte determinada informação relevante e significativa (SANTOS; RIBEIRO, 2012, p. 93). No ambiente da biblioteca universitária, além de sua tarefa primeira de identificar, organizar e disponibilizar documentos que registram a cultura e 0 
conhecimento é tarefa indispensável e associada uma criação documental secundária na forma de catálogos, por exemplo. Também espera-se que ali se produzam documentos para o estabelecimento de suas rotinas, procedimentos e fluxos de trabalho como elaborados manuais, guias aos usuários, tutoriais, políticas, destinados ao uso interno ou ao seu público.

O registro documental das atividades biblioteconômicas faz parte da gestão consistente das bibliotecas. O conjunto de políticas e diretrizes não só esclarece a filosofia e os objetivos que norteiam as práticas diárias e a consistência nas diversas etapas do tratamento bibliográfico e de atendimento ao usuário, mas as articula, fornecendo um sentido cooperativo e agregador de valor a cada etapa de processamento.

Mas também sem tais registros não é possível realizar avaliações periódicas dos resultados das ações e planos e rever os procedimentos que precisem ser readequados à dinâmica própria dos usos da informação e de novas disponibilidades metodológicas, técnicas e tecnológicas. Eles também são fundamentais para dar transparência sobre decisões tomadas pela biblioteca como a distribuição dos recursos informacionais no atendimento aos segmentos de usuários, as decisões sobre escolha de linguagens documentárias para representação de conteúdos, do alcance ou limite da cooperação com outras bibliotecas etc. Estas são decisões que afetam o acesso à informação e, portanto, precisam estar claramente apresentadas e, de preferência, debatidas e obtidas por consenso junto à comunidade atendida.

Este artigo coloca em questão o registro das atividades laborais nas bibliotecas de universidades federais sob o prisma do agir ético do bibliotecário, das diretrizes de políticas informacionais e do acesso à informação. Registros que permitem a padronização das rotinas, identificação possíveis falhas, concepção de novas ações e dão transparência ao público com relação aos procedimentos adotados. 
Além disso, há de se preservar a coerência com um dos pontos essenciais da profissão que é o de ter facilidade para lidar com documentos e sua difusão.

\section{REGISTRO DOCUMENTAL: CONSTRUÇÃO DA MEMÓRIA SELETIVA}

Se bibliotecas também produzem documento, sua conceituação Ihes interessa tanto porque diz respeito a seu objeto direto de trabalho quanto porque diz respeito a seus produtos. O percurso histórico de construção e reconstrução do conceito de documento apresenta aspectos que permitem indagar o que implica o ato de documentar.

$O$ conceito de documento em Paul Otlet era bastante apropriado ao contexto ao qual pertencia, a primeira metade do século $X X$, mas inovador se comparado aos entendimentos dissociados entre arquivos, bibliotecas e museus. Em "Documentos e documentação" isso fica evidente quando o autor insere "novas formas de documento" em suportes audiovisuais (OTLET, 1937). Para definir o que era "documento", portanto objeto apto a ingressar neste grande repertório do conhecimento, Otlet (1996, p. 43, tradução nossa) lança mão dos traços ou características que encontra nos livros para propor um alargamento. "Os livros são ao mesmo tempo o receptáculo e o meio de transporte das ideias." Portanto, tudo aquilo que cumprir esta mesma finalidade deve fazer parte do inventário e ser chamado de documento.

Mas Otlet (1937, p. 2) avança sobre a própria tarefa criadora do documentalista e suas responsabilidades quando diz que "[...] não é bastante [...] à documentação produzir e acumular confusamente; ela deve remontar a seus fins, saber registrar segundo a ciência, saber criar segundo a arte e saber aplicar segundo a utilidade."

Já nos anos 1950, Briet (2006, p. 10, tradução nossa) retoma a conceituação, considerando documento "[...] todo signo (índice) concreto ou simbólico, preservado ou registrado com o fim de representar, 
reconstruir ou provar um fenômeno físico ou intelectual." Mas ao tratar da natureza da produção documentária, Briet (1951) considera que os registros documentais tais como a catalogação, a classificação, ou ainda na construção de instrumentos representativos, como linguagens documentárias, são aqueles possibilitam a origem de novo produto documental. É uma característica interdocumental que aponta que a esta atividade laboral tanto lida com documentos quanto produz documentos. Mais que isto, a tarefa do bibliotecário é documentar. É a documentação que torna um signo uma evidência disponível.

Para Bradford (1961), o ato de documentar é uma "arte" cuja tarefa é reunir novas informações sobre as áreas do conhecimento humano de modo que elas sejam localizadas o mais rápido possível, fazendo uso da coleta e classificação temática (base fundamental). Percebe-se na definição que o autor se preocupa com o acesso à informação pelos usuários. Afirma que a documentação surge como o "[...] resultado da compreensão entre o abismo existente entre o preparo de um registro em qualquer esfera de atividade e a colocação desse registro nas mãos daquele que pode usá-lo como base para uma realização nova." (BRADFORD, 1961, p. 69).

Após os anos 1970, os documentos eletrônicos iriam demandar um deslocamento da centralidade do suporte na noção de documento. Cunha e Cavalcanti (2008, p.132) dividem o conceito "documento" em dois momentos: clássico e posterior a 1970. No primeiro momento, as definições de documento estão presas ao suporte de registro do conhecimento. No segundo, as explicações concentram-se no conteúdo, assunto, na informação. Selecionamos as que mais expressam essa ideia: "Qualquer meio (suporte) onde se encontre registrada a evidência de uma realização intelectual (SENG, 1977 apud CUNHA; CAVALCANTI, 2008, p. 132); "Qualquer parcela do conhecimento ou fonte de informação, seja qual for o suporte utilizado" (ABF apud CUNHA; CAVALCANTI, 2008, p. 132). Santos e Ribeiro (2012, p. 93) também mostram definições nessa linha considerando que o conceito 
mais atual está voltado ao conhecimento, à informação que o suporte transmite: "Unidade constituída pela informação e seu suporte; registro de uma informação independente da natureza do suporte que a contém."

Na perspectiva de construção da memória coletiva e seletiva que se consubstancia no documento, González de Gómez (1999; 2009a) de certo modo retoma Briet (1951), apontando que as ações seletivas que criam informação acontecem quando o agente social agrega valor $\mathrm{e}$ significado à informação disponibilizada por unidades como a biblioteca, com base em suas experiências de vida e percepções, além de ter influência de poderes hegemônicos em voga.

A produção de um documento e de informação é a criação de um artefato cultural, resultante de um processo amplo e complexo que a autora designa por "regime de informação". Aí encontram-se muitas interferências diretas e indiretas de agentes e de valores socialmente reconhecidos como importantes, operando na esfera de produção de artefatos informacionais, que moldam a formação do documento. Os artefatos de informação são produzidos a partir de documentos. Por outro lado, na produção de novos documentos, lança-se mão de artefatos de informação. Há, portanto, uma espécie de circularidade neste processo (GONZÁLEZ DE GÓMEZ, 2003; 2009b).

Acerca da conceituação de documento, Frohmann (2009) reflete sobre seu próprio texto publicado anteriormente acerca dessa temática e conclui que $o$ ato de documentar contém implicações que extravazam as intenções tradicionais que o conceito encerra, de precisão, exatidão e representação científica. O revisitar conceitos é legítimo para dar conta das variáveis, em constante transformação, oriundas da vida social que os influenciam.

Baseada em Frohmann (2009) e González de Gómez (1999), Fernandes (2011) reflete acerca de constituição de uma "política difusa de memória" na realização de práticas documentárias. A autora aborda que $O$ ato de documentar é complexo, sendo muito influenciado por 
fatores externos e internos ao indivíduo, que se apresentam de forma tão difusa que seria difícil distingui-los. Como disse a autora:

\begin{abstract}
Cada ator, cujas práticas seguem critérios institucionalizados e instrumentos aceitos, atua neste circuito como construtor, validador, conformador dos documentos e informações que produzem, assim como são conformados, neste processo produtivo, em documentadores e informantes [...] Documentar, enquanto uma prática produtora de documentos, exige um praticar, e tais práticas são socialmente disciplinadas (FERNANDES, 2011, p. 215).
\end{abstract}

A inclusão ou exclusão de informações nos produtos documentais e a atribuição de valores à informação seriam resultantes tanto de disputas de agentes que interveem com seus interesses na produção de documentos quanto de ações rotineiras instituídas nas práticas do documentar. Numa perspectiva mais recente para a Biblioteconomia e Ciência da Informação, o contexto de produção documental vem sendo muito mais analisado para se compreender o registrar de informações.

Daí se supõe que o conjunto das ações realizadas nas práticas de trabalho biblioteconômicas não estão livres de sofrer influências, muitas vezes imperceptíveis a este profissional, que vão desde a disponibilidade de documentos que se podem identificar para aquisição, como existência e preço, até os instrumentos de informação que podem apresentar termos discriminatórios, privilegiar uma cultura, omitir descritores. Mas que também podem passar por pressões de grupos dentro da instituição e mesmo da direção ou de outras instituições.

Tendo em conta as proposições de González de Gómez (1999) e Frohmann (2009), deve-se considerar que a minimização dos efeitos destas várias influências não pode ficar ao encargo exclusivo dos bibliotecários, porque seria, de um lado, exigir-Ihes demais, de outro, des-responsabilizar a comunidade a quem atendem. Os registros laborais da atividade biblioteconômica apresentam-se como meios de partilha com a comunidade, abrindo às possibilidades de outros olhares e de críticas em vista do acesso à informação. 
A partir deste prisma, realizou-se um mapeamento acerca das recomendações de manter estes registros e de sua existência efetiva em bibliotecas de universidades federais brasileiras, tendo em conta que os aspectos éticos em que estão aí implicados, a avaliação dos resultados de suas ações e sua consonância com a lei acesso à informação.

\section{ASPECTOS ÉtICOS, POLÍtICOS E DE ACESSO À INFORMAÇÃO}

Se a biblioteca universitária trabalha com a organização, representação, divulgação e acesso aos registros do conhecimento, é de se esperar que ela faça o registro dos seus procedimentos administrativos, técnicos e de atendimento ao público. Seria contraditório e incoerente que uma instituição que opera com registros não registrasse sua rotina. Coloca-se em questão a ausência desta prática como um problema ético, como um problema para implementação de uma política pública para estas bibliotecas e como um problema de impossibilidade no atendimento à exigência do acesso à informação em uma instituição pública.

A Classificação Brasileira de Ocupações do Ministério do Trabalho e Emprego (CBO/MET) agrupa na família "2612 - Profissionais de Informação" os bibliotecários, documentalistas e analistas de informações, citando os seus principais sinônimos possíveis e reforçando a necessidade do Bacharelado em Biblioteconomia para exercício da função (BRASIL, 2013) Em cada competência mencionada ao profissional da informação, há uma série de desdobramentos específicos e dentre eles podemos identificar que alguns pressupõem a necessidade de produzir registros documentais no exercício profissional. 
Quadro 1 - Competências do profissional da informação e registro documental de suas ações

\begin{tabular}{|c|c|}
\hline COMPETÉNCIAS & ATIVIDADES \\
\hline $\begin{array}{l}\text { a) Disponibilizar informação } \\
\text { em qualquer suporte }\end{array}$ & $\begin{array}{l}\text { Intercambiar informações e documentos } \\
\text { Controlar circulação de recursos informacionais }\end{array}$ \\
\hline $\begin{array}{l}\text { b) Gerenciar Unidades, } \\
\text { Redes e Sistemas de } \\
\text { Informação }\end{array}$ & $\begin{array}{l}\text { Elaborar programas e projetos de ação } \\
\text { Desenvolver planos de divulgação e marketing } \\
\text { Desenvolver políticas de informação } \\
\text { Controlar a execução dos planos de atividades } \\
\text { Elaborar políticas de funcionamento de unidades, } \\
\text { redes e sistemas de informação } \\
\text { Desenvolver planos de segurança ambiental } \\
\text { Elaborar relatórios } \\
\text { Elaborar manuais de serviços e procedimentos }\end{array}$ \\
\hline $\begin{array}{l}\text { c) Tratar tecnicamente } \\
\text { recursos informacionais }\end{array}$ & Registrar recursos informacionais \\
\hline $\begin{array}{l}\text { d) Desenvolver recursos } \\
\text { informacionais }\end{array}$ & $\begin{array}{l}\text { Elaborar políticas de desenvolvimento de recursos } \\
\text { informacionais } \\
\text { Desenvolver planos de conservação preventiva }\end{array}$ \\
\hline e) Disseminar informação & $\begin{array}{l}\text { Elaborar clipping de informações } \\
\text { Elaborar alerta bibliográfico } \\
\text { Elaborar boletim bibliográfico }\end{array}$ \\
\hline $\begin{array}{l}\text { f) Desenvolver estudos e } \\
\text { pesquisas }\end{array}$ & $\begin{array}{l}\text { Coletar informações para memória institucional } \\
\text { Elaborar dossiês de informações } \\
\text { Realizar estudos cientométricos, bibliométricos e } \\
\text { infométricos } \\
\text { Elaborar trabalhos técnico-científicos } \\
\text { Elaborar estudos de perfil de usuário e } \\
\text { comunidade } \\
\text { Elaborar diagnóstico de unidades de serviço }\end{array}$ \\
\hline $\begin{array}{l}\text { g) Prestar serviços de } \\
\text { assessoria e consultoria }\end{array}$ & Elaborar laudos técnicos \\
\hline $\begin{array}{l}\text { i) Desenvolver ações } \\
\text { educativas }\end{array}$ & $\begin{array}{l}\text { Capacitar o usuário } \\
\text { Capacitar recursos humanos }\end{array}$ \\
\hline
\end{tabular}

Fonte: Brasil (2013).

O Código de Ética Profissional do Bibliotecário, de 11 de janeiro de 2002, não menciona especificamente o compromisso de registro das atividades laborais. Contudo, o artigo $3^{\circ}$ do Código, letra c, menciona como atribuições do profissional de Biblioteconomia "[...] cooperar intelectual e materialmente para o progresso da profissão, mediante o intercâmbio de informações com associações de classe, escolas e órgãos de divulgação técnica e científica." (CONSELHO FEDERAL DE BIBLIOTECONOMIA, 2002). O artigo 8 complementa dizendo que 0 "[...] bibliotecário deve interessar-se pelo bem público e, com tal 
finalidade, contribuir com seus conhecimentos, capacidade e experiência para melhor servir a coletividade." Assim, na produção documental que se infere em suas atribuições não se encontram exigências de produção de registros oficiais de seus procedimentos.

Já a avaliação institucional do INEP/MEC coloca em relevo, para nota máxima no item da Dimensão 7-7.4, que aplica-se à biblioteca, a existência de diretrizes registradas da política assumida por seus profissionais, acessível à comunidade externa e interna, nos quesitos informatização e aquisição / atualização de seu acervo (BRASIL, 2006). Ainda que as avaliações do INEP tenham em vista a qualidade dos cursos de graduação a diretriz não apresenta tal restrição, de modo que se espera minimamente, ao menos ao cumprimento desta, que as bibliotecas se empenhem em formalizar políticas de aquisição e informatização.

Embora não exista hoje uma política pública para as bibliotecas universitárias, ela já existiu. A avaliação de sua eficácia e a proposição de reajustes, ou mesmo da concepção de uma nova política, dependeriam também do acesso a registros de sua execução e resultados locais. Uma política pública é composta por um conjunto de planos, metas e ações estipuladas pelo Estado para resolução de um problema público (DIAS; MATOS, 2012, p. 1-15). O Plano Nacional de Bibliotecas Universitárias (PNBu), originário do Programa Nacional de Bibliotecas Universitárias (PNBU), datado de 1986 é a única política pública para as bibliotecas universitárias brasileiras existente até 0 presente momento.

O PNBu é visto por Silva, A. (2009) e Silva, E. (2009) como parte das políticas de informação científica e tecnológica ocorridas na década de 1980 no Brasil e seu conteúdo esteve fortemente embasado nas discussões e percepções dos bibliotecários universitários que se manifestavam nos Seminários Nacionais de Bibliotecas Universitárias, os SNBUs (CARVALHO, 2004; CHASTINET, 1990). O Plano conteve seis eixos temáticos, todos voltados à estruturação interna das 
bibliotecas, em uma perspectiva organizacional. Mas não previa, entretanto, meios e métodos para documentar as ações realizadas e seus resultados efetivos para um futuro momento de avaliação (BRASIL, 1986a; 1986b).

Quadro 2 - PNBU: eixos e diretrizes

\begin{tabular}{|c|c|}
\hline EIXO TEMÁTICO & DIRETRIZES \\
\hline $\begin{array}{l}\text { 1. PLANEJAMENTO: } \\
\text { ORGANIZACIONAL, } \\
\text { FINANCEIRO, DE } \\
\text { RECURSOS HUMANOS E } \\
\text { FÍSICOS }\end{array}$ & $\begin{array}{l}\text { Estabelecer um sistema de bibliotecas em cada } \\
\text { universidade; } \\
\text { Definir padrões de desempenho (metas) para as } \\
\text { bibliotecas; } \\
\text { Prover recursos financeiros suficientes à sua } \\
\text { prestação de serviços; } \\
\text { Formar e qualificar adequadamente os recursos } \\
\text { humanos; } \\
\text { Dotar a biblioteca de estrutura física adequada à } \\
\text { sua coleção, público e funcionários; }\end{array}$ \\
\hline $\begin{array}{l}\text { 2. FORMAÇÃO E } \\
\text { DESENVOLVIMENTO DE } \\
\text { COLEÇÕES }\end{array}$ & $\begin{array}{l}\text { Formular políticas de constituição, } \\
\text { desenvolvimento e conservação de coleções; } \\
\text { Estimular programas de aquisição cooperativa e } \\
\text { planejada; }\end{array}$ \\
\hline $\begin{array}{l}\text { 3. PROCESSAMENTO } \\
\text { TÉCNICO DOS } \\
\text { DOCUMENTOS }\end{array}$ & $\begin{array}{l}\text { Tratar os documentos de forma padronizada, } \\
\text { racionalizando os procedimentos e favorecendo } \\
\text { intercâmbio entre arquivos; }\end{array}$ \\
\hline $\begin{array}{l}\text { 4. AUTOMAÇÃO DE } \\
\text { BIBLIOTECAS }\end{array}$ & $\begin{array}{l}\text { Estimular a automação dos procedimentos } \\
\text { técnicos e administrativos da biblioteca; }\end{array}$ \\
\hline 5. USUÁRIOS E SERVIÇOS & $\begin{array}{l}\text { Assegurar métodos e técnicas que identifiquem } \\
\text { as necessidades de informação dos usuários e } \\
\text { das IFES. } \\
\text { Assegurar o planejamento e oferecimento dos } \\
\text { serviços de informação de acordo com a } \\
\text { diversidade acadêmica; }\end{array}$ \\
\hline $\begin{array}{l}\text { 6. ATIVIDADES } \\
\text { COOPERATIVAS }\end{array}$ & $\begin{array}{l}\text { Estimular a participação de bibliotecas } \\
\text { universitárias em atividades cooperativas. }\end{array}$ \\
\hline
\end{tabular}

Fonte: Adaptado de Brasil (1986a; 1986b).

Atualmente, a Comissão Brasileira de Bibliotecas Universitárias (CBBU), órgão criado em fins da década e 1980 para auxiliar e representar as bibliotecas universitárias (VICENTI, 2015), não dispõe de diretrizes que visem contribuir, dentre outras, para o registro de atividades nas bibliotecas universitárias. Nos Estados Unidos, a 
instituição que representa e ampara politicamente as bibliotecas universitárias, a Association of College and Reserach Libraries (ACRL, 2014), possui e divulga online seus muitos documentos para auxílio às bibliotecas.

Juridicamente 0 acesso à informação produzida pelos órgãos públicos, incluindo aquelas oriundas de suas atividades internas, já havia sido considerado nos incisos XXXIII do art. 5o, no inciso II do § 3 응 do art. 37 e no $\S 20$ do art. 216 da Constituição Federal (BRASIL, 1988). A preocupação com o viés administrativo-documental foi retomado a partir da promulgação da Lei de Acesso a Informação, nº12.527 de 18 de novembro de 2011 (BRASIL, 2011).

$O$ texto enfoca a necessidade das instituições das três esferas governamentais, incluindo Legislativo e o Judiciário, disporem ao público registros documentais acerca de suas atividades, em consonância aos princípios básicos da administração pública. Em seu II Capítulo, artigo 7ํㅡ, a Lei trata dos direitos de obtenção à informação e os incisos $2^{\circ}$ e $5^{\circ}$ mencionam:

[...] II - informação contida em registros ou documentos, produzidos ou acumulados por seus órgãos ou entidades, recolhidos ou não a arquivos públicos; [...] V - informação sobre atividades exercidas pelos órgãos e entidades, inclusive as relativas à sua política, organização e serviços; (BRASIL, 2011)

Considera-se relevante discutir a necessidade intrínseca das bibliotecas universitárias documentarem seu planejamento e organização com intuito de atender demandas de acesso a informação. Paradoxalmente, é curioso ter-se que reafirmar e problematizar uma questão tão própria desta instituição: sistematizar, organizar e disponibilizar registros do conhecimento.

Ora, se uma biblioteca em universidade federal toma decisões de aquisição, por exemplo, trata-se do gasto de recursos públicos. Mesmo não sendo a compradora direta, os critérios dos quais lançou mão para 
solicitar estas aquisições devem estar explicitados de modo a que tanto a comunidade interna como a sociedade em geral possa ter clareza de sua justeza.

As bibliotecas precisam documentar seus procedimentos administrativos para registro histórico da instituição, da área da Biblioteconomia e também para ser um indicador estatístico e real de suas demandas por infraestrutura e investimentos.

\section{ATIVIDADES LABORAIS REGISTRADAS: EM BUSCA DE EVIDÊNCIAS}

Se uma das funções primárias dos bibliotecários é a organização dos registros do conhecimento não é razoável que bibliotecas registrem e organizem suas atividades e ações em favor das próprias bibliotecas. No processo de busca de evidências, escolheu-se um viés básico da Biblioteconomia, "acesso à informação", reforçado pela recente Lei $n^{0} 12.527$, para averiguar junto às bibliotecas se ele foi efetivado. Após a coleta e análise dos resultados, é necessário pensar em propostas que contribuam para dirimir essa dificuldade da área.

A verificação, que diz respeito ao planejamento e a organização das atividades das bibliotecas universitárias, teve por recorte metodológico uma pesquisa de campo quantitativa, realizada durante o mês de maio de 2014, cuja amostra é composta por bibliotecas em universidades federais. A pesquisa consistiu em verificar se nos endereços eletrônicos dos sítios das bibliotecas universitárias há disponíveis guias de usuários, manuais, regimentos, políticas sobre os serviços prestados, seu planejamento e organização interna.

A possibilidade de existência do registro documental das atividades organizacionais, administrativas e de atenção ao usuário foi verificada por meio do acesso ao website dessas bibliotecas. Foram pesquisadas cinquenta e sete bibliotecas em universidades federais. $O$ critério foi localizar o indicativo de registro documental das atividades de 
Ana Carolina de Souza Caetano; Geni Chaves Fernandes

Registros laborais nas bibliotecas universitárias federais: ética, política e acesso a informação

administração, planejamento e organização expressos por meio das categorias: guias para usuários, manuais de procedimento, plano estratégico, regimento, regulamento, relatórios de gestão ou política de desenvolvimento de coleções (PDC). O resultado da pesquisa apresentou as seguintes ocorrências por regiões:

Gráfico 1 - Registro documental de atividades laborais - BU Norte - 10

IFES

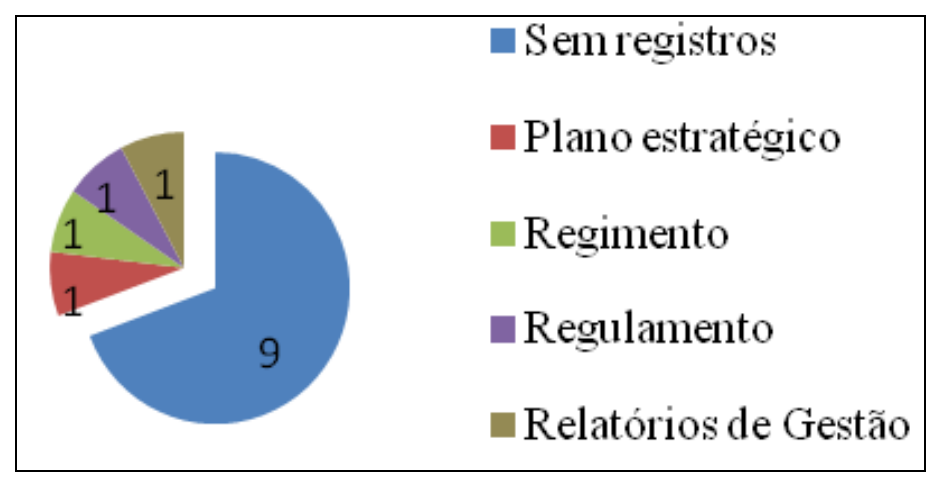

Fonte: Elaborado pelos autores

Gráfico 2 - Registro documental de atividades laborais - BU Nordeste 14 IFES

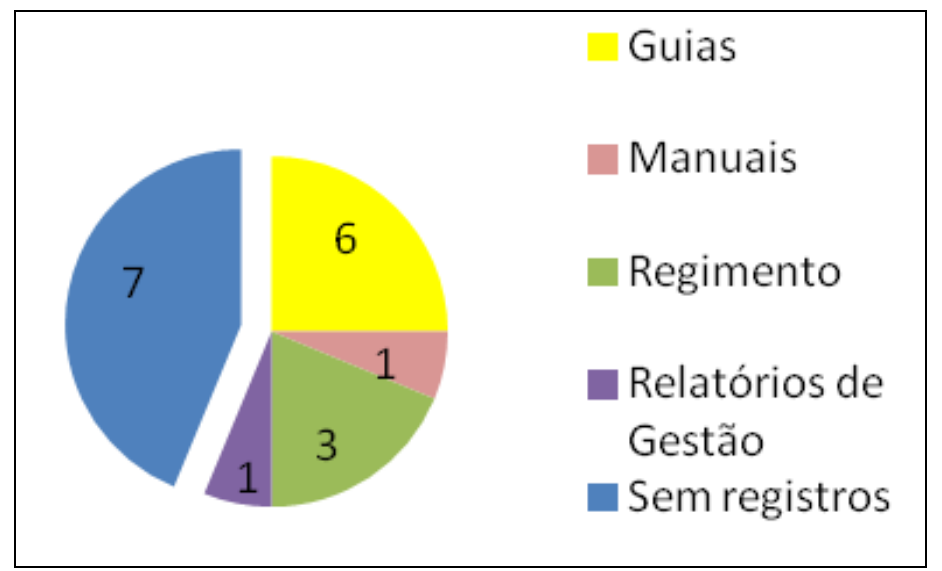

Fonte: Elaborado pelos autores 
Ana Carolina de Souza Caetano; Geni Chaves Fernandes

Registros laborais nas bibliotecas universitárias federais: ética, política e acesso a informação

Gráfico 3 - Registro documental de atividades laborais - BU - CentroOeste -5 IFES

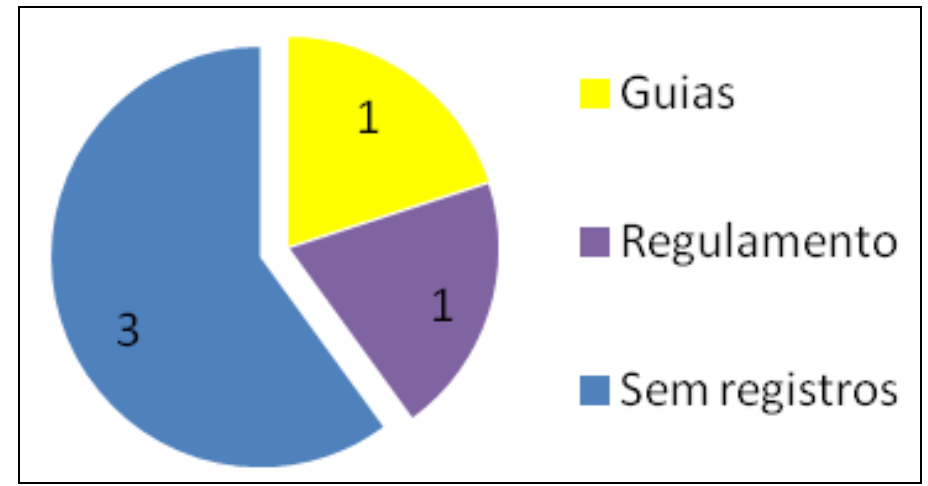

Fonte: Elaborado pelos autores

Gráfico 4 - Registro documental de atividades laborais - BU Sudeste 18 IFES

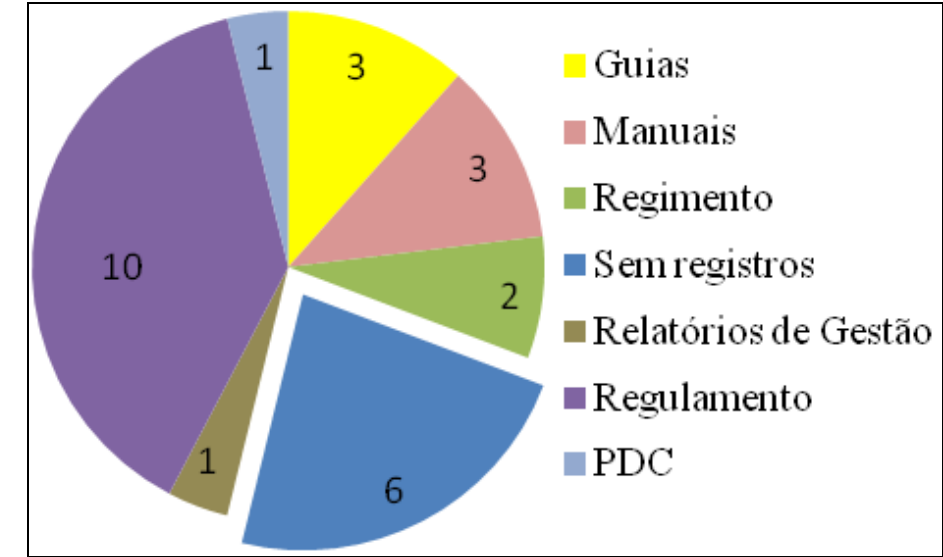

Fonte: Elaborado pelos autores

Gráfico 5 - Registro documental de atividades laborais - BU Sul - 11 IFES

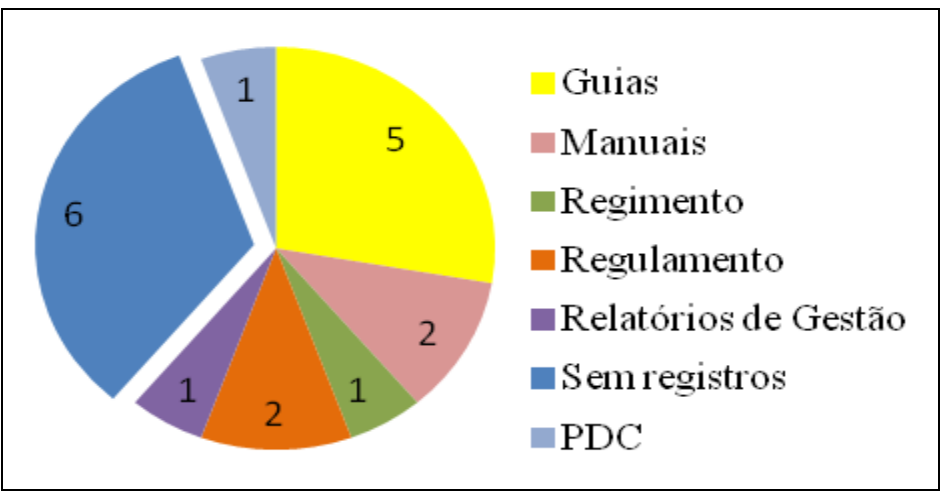

Fonte: Elaborado pelos autores 
Temos que, por região, não possuem quaisquer tipos de registros laborais: $90 \%$ das bibliotecas em universidades federais da região Norte, $54 \%$ da região Nordeste, $60 \%$ da região Centro-Oeste, $33 \%$ da região Sudeste e $56 \%$ da região Sul.

A maioria das bibliotecas em universidades federais do Sudeste e Sul brasileiro possui documentados os seus Regulamentos, seguidos dos Guias de usuários, Manuais e Regimento. Nessas regiões aparece uma maior diversidade de tipos documentais. Apenas $6 \%$ do Sudeste registram suas políticas de desenvolvimento de coleções e seus relatórios de gestão. Trata-se, na verdade de uma uma única biblioteca universitária com estes dois tipos de documentos laborais.

As regiões Nordeste e Norte vêem a seguir, apresentando menor diversidade e porcentagem de registros de atividades laborais. No Centro-Oeste apenas duas instituições possuem registros, tendo uma um Guia e a outra o Regimento.

A situação aponta sérias limitações no âmbito da gestão. Não há o estabelecimento de filosofias e nem de planos administrativos. Ou seja, sem diretrizes e com o aumento de vagas e ingressos pelo REUNI, e avaliações do INEP sobre cursos de graduação que demandam manter número suficiente de exemplares para seu atendimento. Conforme Otlet (1937) não basta "[...] à documentação produzir a cumular confusamente, ela deve remontar a seus fins, saber registrar segundo a ciência [...]."

Em tal quadro, é possível que biblioteca se avolume, mas improvavel que atenda adequadamente a seus usuários Ela não constrói uma ponte sólida sobre o que Bradford (1961, p.69) chama de abismo entre o documento e aquele que pode usá-lo.

Observe-se que os dados apresentados por Busquet (2012, p. 133-134, 147), embora estejam limitados a um estudo de caso, não deixam de ser importantes para alertar para a necessidade o repensar administrativo das bibliotecas universitárias. Para se ter uma ideia, dados da biblioteca central da UFF indicam que, em 1999, com 18.000 
matriculados, o número de cadastrados nas bibliotecas do sistema era de 7500; em 2011 já eram 30.054 matriculados, mas o número de cadastrados tinha diminuído para 4212. Certamente existem outras variáveis influenciando estes resultados, especialmente o acesso direto a fontes via Internet. De qualquer modo, as necessidades de informação não deixaram de existir, mas a biblioteca avolumada não parece atrair os usuários.

A ausência de planos e diretrizes administrativas implica em ineficiência no trabalho e afastamento do usuário, mas implica também em falta de transparência e oportunização de situações injustas, mesmo que não intencionais, e até de falta de ética.

Registros documentais devem ser feitos tendo por pressuposto sua finalidade e utilidade. Os atos laborais das bibliotecas universitárias devem ser publicizados para serem instrumentos norteadores dos usuários internos e externos, para se cumprir a publicidade e acesso à informação dos atos públicos (BRASIL, 1988, 2011; CONSELHO FEDERAL DE BIBLIOTECONOMIA, 2002).

Não documentar as ações e os critérios que norteiam as ações da biblioteca universitária não deixa de ser um modo de ocultamento daquilo que guia as práticas documentárias no interior da unidade de informação. A transparência que se espera nos registros documentais torna mais fácil a identificação de ações e/ou interferências dos agentes sociais envolvidos (GONZÁLEZ DE GÓMEZ, 1999, 2009a). A partir dessa identificação é possível promover maior participação dos interessados nos serviços da biblioteca e buscar meios para amenizar as influências que não sejam de interesse dos usuários na construção dos artefatos informacionais, sendo um deles a própria documentação laboral.

A inexistência, por exemplo, de uma política de indexação oficial e registrada não deixa transparecer quais critérios na escolha de linguagens documentárias, que mais do que representações do mundo são discursos sobre 0 mundo. A falta de uma política de 
desenvolvimento de coleções oficial e registrada pode encobrir, conscientemente ou não, gastos impróprios, favorecimentos de autores, de segmentos de usuários, editoras, empresas, dentre outros. Isso se aplica tanto ao corpo de profissionais que deve poder colocar em questão critérios oficiais e exigir que todos os sigam, assim como abre aos usuários a possibilidade de discordar deles. Poderia se questionar sobre o modo como se distribuem as verbas para aquisições, ou quais os critérios de aquisição e de descarte de itens.

Políticas e registros de tomadas de decisão possibilitam mudanças em critérios da seleção, descarte, distribuição de recursos, indexação, catalogação, cooperação, portanto, que implicam no acesso à informação. Bibliotecas podem e devem abrir ao convite de sua elaboração de modo mais participativo com os grupos de usuários que utilizam os serviços. Políticas e registros de decisão facilitam a análise dos resultados obtidos pelas ações implementadas e, daí, o replanejamento em vista da melhoria constante dos serviços.

Com o atual quadro, esta não é uma tarefa fácil, mas que começa pela indagação: porque os bibliotecários de universidade federais brasileiras pouco realizam registros das atividades laborais? As respostas podem ser muitas, indo da "falta de tempo" à falta de recursos ou até mesmo à falta de preparo. Mas a ausência de diretrizes claras da necessidade de se produzir e disponibilizar tais registros e suas finalidades, que incluem mas transcendem as questões administrativas, em documentos oficiais como o código de ética, o PNBu e do CBBU é uma lacuna que não se pode deixar de ter em conta dentre os motivos desta ausência.

\section{CONCLUSÃO}

$\mathrm{O}$ ato de documentar é, ou deveria ser, muito familiar aos profissionais da informação que lidam com documentos e suas representações. 
As formas de documentar e o seu próprio significado sofreram alterações devido a influências contextuais. A literatura nos elucida que o conceito de documento e a produção documentária se transformaram consideravelmente e que a perspectiva atual nos faz notar a importância das disputas entre agentes e seus interesses no registro de informações. Por isso, evidenciar a escassez e necessidade dos registros formais das práticas profissionais é um modo de reduzir possíveis ações hegemônicas na produção daquilo que vai ser aceito como documento e, a partir disso, como artefato de informação.

Ao discorrermos sobre os aspectos éticos, políticos e de acesso à informação, vimos que poucas são as referências e diretrizes que os bibliotecários dispõem como incentivo, ou cobrança, para realização dos registros de suas atividades laborais. Quiçá espera-se que tal atividade esteja subentendida e não precise de formalidade em sua realização, como é o ato de documentar.

Através da busca por evidências, notamos que o registro das atividades laborais pelas bibliotecas universitárias brasileiras não se faz presente de modo satisfatório e igualmente nas unidades informacionais pelas cinco regiões do país.

Acreditamos que a falta de diretrizes mais claras seja um empecilho a documentação das atividades laborais da biblioteca universitária e que isto implica no livre acesso a informação exigida pela Lei 12.527, bem como se mostra incoerente a profissionais e instituições que teriam, teoricamente, obrigação primária de fazê-lo.

\section{REFERÊNCIAS}

ASSOCIATION OF COLLEGE AND RESEARCH LIBRARIES.

Guidelines and standards. Disponível em: <http://www.ala.org/acrl/standards >. Acesso em: 26 maio 2014.

BATTLES, Matthew. A conturbada história das bibliotecas. São Paulo: Planeta, 2003. 
BRADFORD, S C. Documentação. Rio de Janeiro: Fundo de Cultura, 1961. p. 69.

BRASIL. Constituição da República Federativa do Brasil de 1988. Art. 5, 37 e 216. Disponível em:

<http://www.planalto.gov.br/ccivil_03/constituicao/constituicao.htm >. Acesso em: 26 maio 2014.

BRASIL. Lei n.12.527 de 18 de novembro de 2011. Regula o acesso a informações previsto no inciso XXXIII do art. 5o, no inciso II do $\S 3$ o do art. 37 e no $\S 2$ o do art. 216 da Constituição Federal; altera a Lei no 8.112, de 11 de dezembro de 1990; revoga a Lei o 11.111, de 5 de maio de 2005, e dispositivos da Lei no 8.159 , de 8 de janeiro de 1991; e dá outras providências. Disponível em:

<http://www.planalto.gov.br/ccivil_03/_ato2011-2014/2011/lei//12527.htm >. Acesso em: 26 maio 2014.

BRASIL. Ministério da Educação. Avaliação externa de instituições de educação superior: diretrizes e instrumentos. Brasília, DF: INEP, 2006. Disponível em: <https://www.ufpe.br/ctg/images/avaliacaoexterna.pdf>. Acesso em: 22 jan. 2015.

BRASIL. Ministério do Trabalho e Emprego. Classificação Brasileira de ocupações: 2612 - profissional da informação. Brasília: MTE, 2013. Disponível em: <http://www.mtecbo.gov.br/cbosite/pages/pesquisas/ ResultadoFamiliaAtividades.jsf>. Acesso em: 7 out. 2013.

BRASIL. Portaria no 287 de 24 de abril de 1986a. Disponível em: <http://www.prolei.inep.gov.br/exibir.do?URl=http\%3A\%2F\%2Fwww.ufs m.br\%2Fcpd\%2Finep\%2Fprolei\%2FDocumento\%2F2494772495139594551>. Acesso em: 3 nov. 2010.

BRASIL. Portaria no 288 de 24 de abril de 1986b. Disponível em: <http://www.prolei.inep.gov.br/exibir.do?URl=http\%3A\%2F\%2Fwww.ufs m.br\%2Fcpd\%2Finep\%2Fprolei\%2FDocumento\%2F1630081750154280098 >. Acesso em: 3 nov. 2010.

BRIET, Suzanne. Qu'est-ce La documentation? Paris: Éditions Documentaires Industrielles et Techniques, 1951.

BRIET, Suzanne. What is Documentation? Lanham, MD: Scarecrow, 2006. Disponível em: <http://ils.indiana.edu/faculty/roday/ what\%20is\%20documentation.pdf>. Acesso em: 11 jun. 2014.

BURKE, Peter. Uma história social do conhecimento: de Gutemberg a Diderot. Rio de Janeiro: Jorge Zahar, 2003. 
BUSQUET, Leandro Martins Cota. Bibliotecas universitárias e o impacto das políticas públicas do ensino superior: o caso da BCG/UFF. 167 f. 2012. Dissertação (Mestrado em Ciência da Informação) - Programa de Pós-Graduação em Ciência da Informação, Universidade Federal Fluminense, Niterói, 2012. Disponível em: <http://www.ci.uff.br/ppgci/arquivos/Dissert/Dissertacao_Leandro_Busqu et.pdf> Acesso em: 10 fev. 2013.

CARVALHO, Isabel Cristina Louzada. A socialização do conhecimento no espaço das bibliotecas universitárias. Rio de Janeiro: Interciência, 2004.

CHASTINET, Yone. Participação da comunidade na implantação do Plano Nacional de Bibliotecas Universitárias - PNBU. In: SEMINÁRIO NACIONAL DE BIBLIOTECAS UNIVERSITÁRIAS, 6., 1989, Belém. Anais... Belém: UFPA, 1990. p. 38-56.

CONSELHO FEDERAL DE BIBLIOTECONOMIA. Resolução no 42, de 11 de janeiro de 2002. Dispõe sobre Código de Ética do Conselho Federal de Biblioteconomia. Disponível em: <http://www.crb14.org.br/UserFiles/File/C\%C3\%B3digo\%20de\%20\%C3 \%89tica\%20Bibliotec\%C3\%A1rio.pdf>. Acesso em: 26 maio 2014.

CUNHA, Murilo Bastos da; CAVALCANTI, Cordélia Robalinho de Oliveira. Dicionário de Biblioteconomia e Arquivologia. Brasília: Briquet de Lemos/Livros, 2008.

DIAS, Reinaldo; MATOS, Fernanda. Políticas públicas: princípios, propósitos e processos. São Paulo: Atlas, 2012.

FERNANDES, Geni Chaves. Ações de informação e práticas documentárias como políticas difusas de memória. InCID, Ribeirão Preto, v. 2, n. 1, p. 208-226, jan./jun. 2011. Disponível em: <http://www.revistas.usp.br/incid/article/view/42342/46013 >. Acesso em: 11 jun. 2014.

FROHMANN, Bernd. Revisiting "what is a document?". Journal of Documentation, London, v. 65, n. 2, p. 291-303, 2009. Disponível em: <http://www.emeraldinsight.com/journals.htm?articleid=1776323>. Acesso em: 23 ago. 2013.

GONZÁLEZ DE GÓMEZ, Maria Nélida. A reinvenção contemporânea da informação: entre o material e o imaterial. Tendências da Pesquisa Brasileira em Ciência da Informação, Brasília, v. 2, n. 1, p. 115-134, jan./dez. 2009a. Disponível em: <http://repositorio.ibict.br/bitstream/ 123456789/116/1/GonzalezGomezTendencias2009.pdf >. Acesso em: 11 jun. 2014. 
GONZÁLEZ DE GÓMEZ, Maria Nélida. As relações entre ciência, Estado e sociedade: um domínio de visibilidade para as questões da informação. Ciência da Informação, Brasília, v. 32, n. 1, p. 60-76, jan./abr. 2003. Disponível em:

<http://www.scielo.br/pdf/ci/v32n1/15974.pdf >. Acesso em: 11 jun. 2014.

GONZÁLEZ DE GÓMEZ, Maria Nélida. Desafios contemporâneos da Ciência da Informação: as questões éticas da informação. In: ENCONTRO NACIONAL DE PESQUISA EM CIÊNCIA DA INFORMAÇÃO, 10, 2009, João Pessoa. Anais... João Pessoa: UFPB, 2009b. Disponível em: <http://repositorio.ibict.br/bitstream/123456789/313/1/GONZALEZdeGO MEZENANCIB2009.pdf >. Acesso em: 11 jun. 2014.

GONZÁLEZ DE GÓMEZ, Maria Nélida. O caráter seletivo das ações de informação. Informare, Rio de Janeiro, v. 5, n. 2, p. 7-31, 1999. Disponível em: Acesso em: 11 jun. 2014.

OTLET, Paul. El tratado de Documentación: el libro sobre el libro: teoría y práctica. Trad. por Maria Dolores Ayuso García. Murcia: Universidad de Murcia, 1996. p.43.

OTLET, Paul. Documentos e documentação. Paris, 1937. Disponível em: <http://www.conexaorio.com/biti/otlet/>. Acesso em: 23 ago. 2013.

SANTOS, Gildenir Carolino; RIBEIRO, Célia Maria. Acrônimos, siglas e termos técnicos: arquivística, biblioteconomia, documentação, informática. 2. ed. Campinas: Átomo, 2012.

SILVA, Angela Maria Moreira. Bibliotecas universitárias federais da Amazônia: desbravando fronteiras, administrando improvisos. $174 \mathrm{f}$. 2009a. Dissertação (Mestrado em Políticas Públicas) - Programa em Políticas Públicas, Universidade Federal do Maranhão, São Luiz, 2009a. Disponível em: $<$ http://www.tedebc.ufma.br//tde_busca/arquivo.php?codArquivo=386 > . Acesso em: 24 abr. 2012.

SILVA, Edilene Maria da. A influência das políticas de informação científica e tecnológica para as bibliotecas universitárias. 2009b. 103 f. Dissertação (Mestrado em Ciência da Informação) - Universidade Federal da Paraíba, João Pessoa, 2009b. Disponível em: <http://eprints.rclis.org/14433/1/Disserta\%C3\%A7\%C3\%A3o_Cl_EDILENE_MARIA_DA_SILVA.pdf >. Acesso em: 20 jul. 2013. 
VICENTI, Luiz Atilio. O CBBU junto com as Bibliotecas Universitárias em um novo contexto de criação. Disponível em:

$<$ https://www.periodicos.capes.gov.br/images/documents/Apresenta\%C3 \%A7\%C3\%A30\%20CBBU_Luiz\%20Atilio\%20Vicentini.pdf>. Acesso em: 11 jun. 2015.

WEITZEL, Simone da Rocha. Desenvolvimento de coleções: origem dos fundamentos contemporâneos. TransInformação, Campinas, v. 24, n. 3, p. 179-190, set./dez. 2012. Disponível em: <http://www.scielo.br/pdf/tinf/v24n3/ a03v24n3.pdf >. Acesso em: 26 maio 2014.

\title{
Title
}

Records working in libraries of federal universities: ethics, politics and access to information

\begin{abstract}
Introduction: The librarian work also relates to the registrations of their working procedures. In addition to the efficiency in the management and consistency of work, they give transparency to the guidelines and choices made, and allow periodic reassessment of the shares. Classical authors, who conceptualize the document, emphasize the importance of the act of documenting.

Objectives: Maps the existence of records of employment policies, and actions, in Brazilian federal universities libraries and inquire about the ethical problems, and of the lack of access to information in his absence.

Methodology: Mapping the sites of fifty-seven federal universities libraries searching the provision of official records containing policies, plans, manuals, user guides, regulations, among others.

Results: $57 \%$ of libraries do not offer any kind of record. The greater supply of different working documents is found in the libraries of the Southeast and South. But still, $41 \%$ of them does not provide any kind of document. The lack of transparency can create opportunities of injustices and even unethical actions.

Conclusions: Among the reasons for not document we find the lack of clear guidelines on official documents to drive the profession and the university librarians. It contradicts the principle of the law of access to information and shown inconsistent with professionals and institutions that would theoretically primary obligation to do it.
\end{abstract}

Keywords: Ethics and transparency. Administrative policies. University libraries. 


\section{Titulo}

Registros de trabajo en las bibliotecas de las universidades federales: ética, política y acceso a la información

\section{Resumen}

Introducción: La practica bibliotecaria también se refiere al registro de sus procedimientos de trabajo. Además de la eficiencia en la gestión y la coherencia del trabajo, dan transparencia a las directrices y decisiones tomadas y permiten una evaluación periódica de las acciones. Autores clásicos, que conceptualizan el documento, hacen hincapié en le importancia del acto de documentar.

Objetivos: Mapa de la existencia de registros de las políticas de empleo y acciones en las bibliotecas de universidades federales brasileñas y pedir información sobre los problemas éticos y la falta de acceso a la información en su ausencia.

Metodología: Mapearan-se en los sitios de cincuenta y siete bibliotecas en universidades federales la provisión de los registros oficiales contiendo las políticas. planes, manuales guías de usuarios, reglamentos, entre otros.

Resultados: $57 \%$ de las bibliotecas no ofrecen ningún tipo de registro. La mayor oferta de diferentes documentos de trabajo se encuentra en las bibliotecas del Sudeste y Sur. Pero aún así, 41\% de ellas no proporcionan ningún tipo de documento. La falta de transparencia puede crear oportunidades de injusticias e incluso acciones no éticas.

Conclusiones: En los motivos por los que no se documenta, esta la falta de directrices claras sobre los documentos oficiales que guíen los profesionales bibliotecarios y los de la universidad. Esto contradice el principio de la ley de acceso a la información y se muestra inconsistente para profesionales y instituciones que tendrían teóricamente la obligación primaria de hacerlo.

Palabras Clave: Ética y la transparencia. Políticas administrativas. Bibliotecas universitarias.

Recebido em: 07/08/2014

Aceito em: 17/05/2015 